\title{
O PESQUISADOR CONVERSADOR NO COTIDIANO
}

\author{
Peter Kevin Spink \\ Fundação Getulio Vargas, São Paulo, Brasil
}

\begin{abstract}
RESUMO: Partindo da proposta de que o cotidiano é tudo que temos, de que só há lugares e micro-lugares entendidos enquanto pequenas sequiências de eventos e nada mais além disso, o trabalho aprofunda suas consequiências para a pesquisa em psicologia social focalizando não somente os lugares e suas re-descrições mas também o reposicionamento do pesquisador no cotidiano como somente um entre muitos membros competentes de uma comunidade moral, que busca argüir e agir para melhorias, tal como também fazem as outras.
\end{abstract}

PALAVRAS-CHAVES: Cotidiano; micro-lugares; verdades; sentidos.

\section{THECONVERSING RESEARCHER INEVERYDAY LIFE}

ABSTRACT: This paper examines the implications for social psychology of the proposal that the day-to-day is all we have, that there are only places and micro-places understood as small sequences of events and nothing more and goes on to look at the implications for the researcher in everyday life seen as simply yet another competent member of a moral community.

KEYWORDS: Everyday; micro-places; truth, meaning.

Chiang Yee, escritor chinês e excelente narrador de contos, passou o período de espera no início da segunda guerra mundial na Inglaterra e documentava suas observações no livro 'The silent traveller in war time' $[O$ viajante silencioso em tempos de guer$r a, 1939]$. Um dos contos era sobre os residentes de Londres no verão do 'vai - não vai' quando, na antecipação daquilo que poderia vir (e lembrando a primeira guerra mundial), mascaras de proteção contra gás foram distribuídas para toda a população em pequenas caixas de papelão que as pessoas carregavam para onde fossem. Acompanhava o texto o desenho de um escriturário, num daqueles dias raros e bonitos de verão inglês quando a temperatura sobe para mais de 18 graus centígrados, esticado na grama de um parque no centro da cidade, vestido de camisa e gravata, com o paletó dobrado cuidadosamente a seu lado e com os braços atrás da cabeça para servir de travesseiro - tomando seu banho de sol usando sua mascara de gás.

O que é o cotidiano? Será que a expressão se refere a algo simplesmente mundano, uma parte corriqueira e irrelevante da vida, separada e distinta dos acontecimentos importantes ou, ao contrário, o cotidiano é tudo que temos? Argumentamos que todos vivem no seu cotidiano sejam eles presidentes, prefeitos, reis e rainhas, chefes, escriturários, moradores de rua ou qualquer um de nós. Podemos, no jogo dos sentidos, valorizar o cotidiano de alguém como sendo importante no sentido institucional; mas esta é uma questão diferente. Ao contrário, propomos que todos nós, independentemente de onde estamos e quem somos, acordamos pela manhã e entramos no dia que temos pela frente; dia este que nada mais é que um fluxo de fragmentos corriqueiros e de acontecimentos em micro-lugares.

A idéia de um micro-lugar é uma idéia figurativa ou metafórica mais do que uma definição objetiva (Menegon \& Spink, 2005). Seu propósito é de chamar atenção para a importância do acaso diário, dos encontros e desencontros, do falado e do ouvido em filas, bares, salas de espera, corredores, escadas, elevadores, estacionamentos, bancos de jardins, feiras, praias, banheiros e outros lugares de breves encontros e de passagem. Com a expressão "micro-lugares", buscase recuperar a noção da psicologia social como prática social, de conversa e de debate, de uma inserção horizontal do pesquisador nos encontros diários - encontros estes que não acontecem no abstrato ou no ar, mas que acontecem sempre em lugares, com suas socialidades e materialidades (Law \& Mol, 1995). Até o mundo dito virtual é composto de múltiplos micro-lugares, de um fluxo de pedaços frouxamente interconectados. Alguém pode estar sentado numa cadeira na frente de seu computador de escritório e o outro numa praça, com um computador portátil e uma conexão sem fio fornecida gratuitamente pelo município; mas estão em lugares e eles somente podem se 
conectar porque há também fios, servidores de conexão, protocolos, regras cooperativas de transito eletrônico (Lessig, 2002) - para não esquecer das empresas fornecedoras de equipamento e de energia elétrica ou prefeituras preocupadas com a desigualdade de acesso. Podemos chamar esta mescla de socialidades e materialidades de espaço virtual porque suas relações não são diretas mas, mesmo assim, continuará afetando a camada de ozônio.

Os micro lugares e seus diferentes horizontes são produtos e produtores de vários processos sociais e identitários: nós, eles, os temas a serem debatidos, com quem conversamos, como e onde vivemos. Denso, o cotidiano se compõe de milhares de micro-lugares; não é um contexto eventual ou um ambiente visto como pano de fundo. Os micro lugares, tal como os lugares, somos nós; somos nós que os construímos e continuamos fazendo numa tarefa coletiva permanente e sem fim.

Virar as costas para o cotidiano é abrir mão da possibilidade de uma inserção mais caótica no mundo das ações sociais; uma inserção ordinária e corriqueira - diferente da daquela do especialista e do observador imparcial. O apelo figurativo para os micro-lugares é um apelo para a importância dos pesquisadores se conectarem com os fluxos constantes de pessoas, falas, espaços, conversas e objetos, de assumir-se como também actante (Latour, 2004), parte de um processo continuo de negociação, resistência e imposição de sentidos coletivos. Ao utilizar a noção de micro, não estamos propondo que há também uma noção oposta e separada, um macro em contraposição ao micro. Pelo contrário, propomos que só há lugares entendidos enquanto pequenas seqüências de eventos e que não há mais além disso. Um aperto de mão por exemplo, é co-constitutivo da noção da cordialidade enquanto processo social. Mas a cordialidade não habita outro lugar além do aperto de mão - poderíamos até chamá-lo de macro conceito, mas seu lugar está no cotidiano. A cordialidade aparece em distintas maneiras em diferentes lugares e micro-lugares: na igreja, na festa, na escola, na rua e, para todos efeitos práticos, é lá que é produzido, reproduzido e re-negociado. Apertos de mão, tapinhas nas costas e beijos no rosto abrem espaço para as batidas de palma com palma e outras invenções sociais, oriundas de diferentes contra-culturas num processo de negociação cotidiano que também assistiu o declínio do cumprimento do chapéu ou o beijo na mão, para não esquecer as diferentes reverências de épocas anteriores.

Neste texto, nosso objetivo é aprofundar as consequiências para a pesquisa em psicologia social desta visão propositalmente radical sobre o cotidiano e os micro lugares, focalizando não somente os lugares e suas re-descrições mas também o reposicionamento do pesquisador como simplesmente um entre muitos membros compe- tentes de uma comunidade moral, que busca argüir e agir para melhorias, tal como também fazem muitos outros. Optamos por um estilo de narrativa recortada com pequenos exemplos como forma de demonstrar a importância dos fragmentos na pesquisa social situada.

\section{Lugares e Fragmentos}

Bauman (2005) conta a historia de um censo nacional na Polônia pouco antes da segunda guerra mundial. Dado que a Polônia era uma sociedade multi étnica, os pesquisadores do censo eram instruídos a perguntar sobre a auto-identificação das pessoas em termos de identidade étnica ou nacional. Em mais de um milhão de casos, os pesquisadores falharam, mesmo após longas explicações sobre etnia ou nacionalidade. As pessoas responderam que eram "daqui”, "somos deste lugar", "pertencemos a este lugar". Dada a quantidade de respostas deste tipo, os organizadores do censo não tiveram outra opção a não ser acrescentar "pessoas do lugar" à lista oficial de nacionalidades e etnias. Lugar na língua portuguesa também tem as suas surpresas. Para a grande maioria de pessoas no Brasil, lugar se refere a um local específico: o lugar do evento, ou o lugar do lugar. Esquecemos que em Portugal, além destas possibilidades há também uma outra. Um "Lugar" se refere institucionalmente a um pequeno agrupamento de casas, mais ou menos contíguas (Marques, 1985) e faz parte do mundo cívico sub-nacional junto com as "Freguesias" e "Concelhos" (por exemplo, Lugar da Banduja na Freguesia de Mesão Frio no Concelho da Régua). Na França, apesar dos esforços constantes a partir de Napoleão para centralizar e dar ordem ao estado nacional, o vin du pays permanece sendo o vinho do lugar, uma referência àquilo que é produzido dentro do horizonte do dia a dia; tal como esta padaria nos subúrbios de São Paulo.

É uma padaria aberta para a rua; as padarias eram sempre assim, mas hoje talvez alguém a descreveria como tradicional. Há um balcão na forma de 'U' para tomar café, refrigerantes e lanches etc. As pessoas podem ficar sentadas no balcão ou de pé. Tem também um outro balcão que vende pão e leite formando um 'L' com um balcão de queijos e alguns frios e, no meio, uma gôndola com biscoitos e outros produtos secos. Entre o 'U' e o 'L' se situa o caixa, com vidro e prateleiras com cigarros, balas, drops e outras iguarias. Você deve reconhecer o lugar, às vezes o caixa muda de posição e, às vezes, há somente um balcão grande que segue a linha da parede. Às vezes, fica na esquina de duas ruas e há sempre um jornaleiro por perto e, freqüentemente, um ponto de jogo. Não há portas; as grades são levantadas durante o dia deixando todo o acesso livre e são fechadas à noite a padaria é uma extensão da rua e a rua é uma exten- 
são da padaria. Eu entro, a padaria está cheia porque são 07.30 da manhã e há por ali muitas pessoas diferentes. Algumas tomam um café, outras um lanche reforçado, uma cachaça, um refrigerante e assim vai. Escuto o barulho perto do caixa: 'um Hollywood e um café...', 'já tomou?', 'não...', 'sai um café pago...', '. . . são dois pão com manteiga na chapa e um pingado, ah e ...quero uma dúzia de pãezinhos e um saquinho de leite', '. . . uma dúzia de pãezinhos pago e um leite...', 'um café, obrigado...', 'foram quatro pãezinhos e uma coca cola e eu quero um Dentyne'. Do balcão em 'U' vem vozes parecidas e também do balcão de pão.. 'um misto e um café a pagar'... 'me dê um café, já está pago'... 'eu quero um pão com manteiga na chapa e um café - e quero um bolinho de queijo também, coloque aqui porque vou pegar drops na caixa'... 'tio, me vê quatro pãezinhos e um litro de leite, por favor' 'um misto quente e um pingado a pagar' 'são dois pãezinhos já paguei... ah mas vou levar trezentos de mortadela - quanto mais?'

Na padaria você pode pagar antes de comer, depois de comer, no meio, pegar um pedaço de papel com o preço de seu presunto fatiado e sua dúzia de pãezinhos, ir tomar um café e chegar no caixa para pagar o valor anotado no papelzinho e adicionar a sua palavra sobre o café. Claro, o caixa está observando o movimento e o balconista também; mas quando o movimento aperta, os gritos de 'sai um pingado pago', 'oito e cinquienta no balcão', 'uma dúzia a pagar', têm tanta relevância específica quanto o bemte-vi anunciando o nascer do sol urbano. A padaria funciona porque reina no seu ambiente o pressuposto moral que as pessoas vão pagar por aquilo que consumiram e que vão consumir aquilo pela qual pagaram. A padaria como micro lugar, é um evento do cotidiano, parte da vida coletiva - ser mentiroso na padaria seria equivalente a fumar durante a missa.

Entretanto, pouco a pouco emerge uma outra padaria; a padaria butique toda fechada com pães diferentes, frios variados e não somente o básico presunto, mortadela, mussarela e queijo prato. Você recebe uma ficha na porta e o pagamento é na saída. Há variações, algumas usam ficha de plástico do tipo lanchonete rodoviária e outras fichas de papel onde cada balconista anota o gasto. A posição do freguês mudou. Não é mais um membro da padaria cuja honestidade e memória mantém a coletividade; virou um simples carregador de um pedaço de papel ou cartão de balcão para balcão. Não pode mais deixar seu lanche e café no balcão por um momento para sair e comprar jornal porque agora a saída é restrita e só se sai ao pagar. O jornaleiro continua lá, mas parou de ser parte do evento. (Re-descrição feita a partir das anotações do autor).

Para o pesquisador, a noção de micro lugares é um duplo desafio: primeiro de aprender a prestar atenção a nossa própria cotidianidade, reconhecendo que é nela que são produzidos e negociados os sentidos e, segundo, de aprender a fazer isso como parte ordinária do próprio cotidiano, não como um pesquisador participante e muito menos como um observador distante, mas simplesmente como parte. Se o primeiro já é difícil o segundo desafio requer a disposição de repensar muito daquilo que é presumido como central à "boa pesquisa científica". Quando José Agnaldo Gomes (2005) acompanhava o dia a dia de um movimento urbano em São Paulo de pessoas em situação de rua que mais tarde viraria um assentamento agrícola urbano-rural, ele relatou que um certo dia ele e outras pessoas do movimento estavam jogando conversa fora na beira da estrada quando ele virou para alguém e falou, "eu preciso marcar uma entrevista contigo". A resposta veio imediatamente, "o que é isso seu Guinaldo, por que entrevistar?... o que podemos é conversar". Quando a "conversa comprida" do trabalho de campo de Malinowski nas Islas Trobriand (1914-1918) foi transferida por Park para a urbanidade de Chicago em 1925, consolidou-se a idéia de que para trabalhar na sua própria cultura ou lugar era necessário tornar aquilo que estava sendo observado um lugar estranho, "tornar o outro um estrangeiro" a partir de noções como "distância", "separação" e "objetividade". Curioso é o contraste desta definição implícita de objetividade com o que fazemos no cotidiano. No cotidiano, pessoas que se encontram pela primeira vez normalmente buscam se conhecer, incluindo aqui os psicólogos sociais quando não estão se esforçando para serem psicólogos sociais. Buscam, em outras palavras, chegar mais perto, conhecer o outro e trocar figurinhas para ter uma visão mais objetiva um do outro, conhecer seus pontos de vista e de onde falam; ou seja, uma objetividade construída intersubjetivamente (Habermas, 1984). O problema portanto não é com a objetividade em si, mas em como é entendida.

Ao contrário dos métodos planejados em que se delineia a priori um roteiro de perguntas sobre um tema previamente acordado e operacionalmente definido, ser um pesquisador no cotidiano se caracteriza freqüentemente por conversas espontâneas em encontros situados. Leny Sato (1991, 2007), passou horas viajando nos ônibus urbanos, batendo papos com motoristas na sua investigação sobre trabalho penoso e repetiu o mesmo processo com seu estudo recente das feiras livres onde as frutas e verduras também faziam parte das conversas e se fizeram presentes nos relatos e nas fotos. Jesus Canelon Perez (2004) andava rio acima com um juiz de água na zona rural da Venezuela conversando sobre a noção de água como um bem coletivo. No processo, pequenos momentos foram gravados na memória, acontecimentos não planejados, associações entre o social e o material, entre as redes frouxas de sentidos que conectam os pedaços do dia a dia. São os pequenos momentos do fluxo diário, abertos às possibilidades da 
convivência cotidiana; são fragmentos, às vezes de conversas, às vezes de acontecimentos, às vezes de pedaços de materialidade, às vezes de documentos que nos chegam às mãos e às vezes de relatos na mídia. Segue um destes momentos; no caso, um fragmento de conversa ocorrida na mesa de um bar.

Vera: o tema da minha pesquisa é menopausa.

Rafael: menopausa? Que assunto horrível.

Vera: o que isso faz você lembrar?

Rafael: sei lá... mas fico pensando que a mulher deve sofrer muito...é como se fosse um aleijão.

Vera: aleijão? Não entendi.

Rafael: é como alguém perder uma perna, um braço. A mulher perde a capacidade de gerar um filho, fica como uma árvore seca. (Menegon, 1999, p. 238).

Vera (Menegon) pesquisava o tema da menopausa e Rafael é um psicólogo clínico, amigo de faculdade. A conversa aconteceu na mesa de um bar. Provavelmente, se a pesquisadora tivesse marcado um horário para entrevistar Rafael em seu consultório, buscando entender os sentidos de menopausa que circulam entre os psicólogos, a conversa seria outra. Nenhuma delas seria a correta, ambas são conversas situadas; ambas são micro lugares.

\section{Uma Outra Perspectiva sobre o Campo}

A visão clássica e ainda dominante de "campo" na psicologia social é de um lugar onde as pessoas podem ser vistas no seu habitat "natural", que existe num lugar específico, e quando o pesquisador não está mais naquele lugar, não está mais no campo. Estar no campo pode ser um período intenso de viver junto, ou simplesmente uma série de visitas; e há disputas interdisciplinares sobre o quanto de tempo constitua um trabalho de campo "de verdade".

Kurt Lewin (1952) usou "campo" de outra maneira, para se referir à análise de situações e às constelações de forças psicológicas e não psicológicas presentes. Campo para Lewin, era uma teia de efeitos:

Hábitos alimentares não acontecem em espaços vazios. São parte integrante do ritmo diário de acordar e dormir; de estar sozinho e num grupo; de ganhar a vida e de brincar; de ser um membro de um município, uma família, uma classe social, um grupo religioso, uma nação; de viver num clima quente ou frio; numa área rural ou numa cidade, num distrito com bons supermercados e restaurantes ou numa área onde o abastecimento é pobre e irregular. De alguma maneira todos estes fatores afetam os hábitos ali- mentares num determinado momento. (Lewin, 1952, p. 174, tradução do autor).

Lewin, entretanto, não chegou à temática dos hábitos alimentares por acaso. Ao contrário, se envolveu com a questão porque achou que era algo com que os psicólogos sociais poderiam contribuir. Esta é a noção de campo que discutimos em texto anterior (P. Spink, 2003) apontando que, quando Lewin entrou na questão de hábitos alimentares, ele se colocou dentro do campo do tema dos hábitos alimentares, passando a fazer parte de seu cotidiano. Tanto faz se ele estava observando crianças, lendo seu jornal diário, conversando com colegas ou comendo com a sua família; ele estava presente no campo-tema dos hábitos alimentares, pronto para argumentar que a idéia de hábitos alimentares era uma idéia útil e, do ponto de vista da psicologia social, socialmente relevante.

Se Lewin fosse nutricionista, ou antropólogo, um mestre de cozinha ou um membro de um movimento contra fast food, também teria se colocado dentro do campo dos hábitos alimentares da mesma maneira que faria um pai ou uma mãe ou professora que discute a questão da merenda escolar. Ao se inserir no campotema, sustenta-se o campo-tema, mantendo-o socialmente presente na agenda das questões diárias. Alguns campotemas (a idéia social da importância de um conjunto de preocupações e o argumento a favor da utilidade de uma expressão específica como forma de referenciar, vincular e relacionar eixos e assuntos vinculados) foram declarados socialmente relevante tantas vezes que corremos o risco de presumi-los como óbvios, como fatos tornados objetos, independentes e autônomos, esquecendo que, como idéias, elas não crescem num vácuo. Há muito pouco tempo, o lugar das crianças era na rua, era lá que brincavam. Agora as "crianças de rua” são uma questão social.

Quando pessoas que se definem como pesquisadores se encontram - sejam elas psicólogos, sociólogos, biólogos, historiadores ou qualquer outro - eles normalmente se perguntam mutuamente sobre suas respectivas áreas de estudo. Quando alguém responde, por exemplo, que está trabalhando com as maneiras diferentes em que as declarações e estatutos internacionais e nacionais sobre as crianças e adolescentes discutem as crianças e os adolescentes (Bertuol, 2003), está também argüindo que este é um tema importante e, simultaneamente, se posicionando dentro da temática. Da mesma maneira, alguém que perguntou para Kurt Lewin "quais as novidades?" provavelmente recebeu a resposta "hábitos alimentares". Não estamos no campo porque fomos para um lugar distante, porque fomos visitar um centro comunitário, passar o dia num posto de saúde ou ficamos na fila para receber senha no serviço de intermediação de empregos. Estamos no campo porque estamos no campotema como matriz de questionamento e argumento, de 
ação e narração (Garfinkel, 1967). Tanto faz se estamos trabalhando com um financiamento científico, trabalhando com organizações advocatórias ou em projetos de pesquisa-ação, escrevendo, conversando, olhando anotações, participando de comissões assessoras, dando palestras ou tomando uma cerveja numa sexta feira à noite e argüindo com amigos; estamos no campo-tema buscando contribuir para o bem coletivo, assumindo a nossa parte numa comunidade moral mais ampla.

Entendido desta maneira, torna-se claro que não estamos sozinhos no campo-tema; ao contrário, estamos juntos com muitos outros, inseridos e posicionados de maneiras diferentes. Membros de Conselhos Municipais para os Direitos das Crianças e dos Adolescentes, juizes, membros da Pastoral da Criança; Rafael como psicólogo clinico e como colega de graduação numa mesa de bar; fabricantes de caixas de papelão de mascaras de gás, jornalistas que criam a expressão "a guerra falsa", organizadores do censo Polonês com suas idéias demográficas sobre nacionalidade e etnia, o dono da padaria, os trabalhadores da construção civil dos prédios de luxo ao lado e um psicólogo social que chegou cedo para uma conversa com um Secretario de Estado e foi tomar um café na padaria.

Também não somos as únicas pessoas que buscam formas de narrar e contar o cotidiano; como qualquer leitura dos grandes escritores de contos brasileiros rapidamente demonstraria ou dos pequenos ensaios de Roland Barthes (1982) escritos mensalmente entre 1954 e 1956 sobre alguns dos mitos da vida cotidiana francesa habilmente demonstram. Há fotógrafos, pessoas editando vídeo documentários, músicos e poetas, cada um buscando trabalhar com fragmentos diários, além de todas as pessoas que, nas conversas sobre os acontecimentos do dia a dia, mantém viva a arte de contar histórias. Se hoje se discute a comunidade das idéias, tornando a produção intelectual cada vez mais coletiva, aberta e interconectada (o copy-left em vez do copy-right), um fluxo geral de fragmentos e noções, formando e disputando sentidos numa ecologia de saberes (Sousa Santos, 2007) - por que devemos nos considerar especiais?

Celso Athayde, empresário de rap e hip-hop e um dos fundadores da Central Única de Favelas (CUFA) participou junto com o rapper MV Bill no projeto de filmagem e entrevistas com jovens que trabalham no tráfico de drogas que resultou no documentário Falcão - Meninos do tráfico. Parte da experiência de gravação foi relatada no livro Cabeça de porco (Athayde, 2005).

Chegamos no estado da Paraíba para descobrir a realidade daquele lugar. Saltamos no aeroporto e pegamos um barco para chegar a uma das favelas que escolhemos. Não havia critérios muito claros para essa escolha. Era muito mais na base da intuição e das notícias que tínhamos tido, quando fizemos show nesses lugares. Não queríamos desprezar o formato convencional das pesquisas sobre violência, queríamos apenas aproveitar a vantagem de não saber a forma convencional para não parecer com os intelectuais que tentam patentear as favelas com números absurdos, números que viram verdades quando vão pra mídia e não são contestados por ninguém. . . Chegamos à favela e vimos alguns jovens jogando futebol, ao lado de um conjunto residencial, ou melhor, palafitas. Não era possível que existisse tráfico ali. Era muita miséria, muita desnutrição, muita desgraça. Será que ali também haveria crack sem ser de bola? Deus, não deixa que tenha... meu coração suplicava - sem que ninguém ouvisse - que não houvesse e que nossa viagem fosse uma decepção. Bobagem minha, pura tolice. Bastou escurecer e os moleques estavam lá, na pista, com seu jeito diferente, seus sotaques próprios, mas estavam lá. . . Mas uma coisa era certa: aquilo que eu achava que era uma desgraça, de certa maneira fazia parte da economia daquele lugar; o dinheiro que entrava ali naquele bairro produzia uma grande quantidade de violência, exatamente porque produzia a riqueza e a ganha-pão de todos eles. Tudo muito confuso, tudo muito doido. . . Fizemos entrevistas com uns três moleques no primeiro dia. Fiquei muito impressionado com eles, com a frieza, a segurança e a seriedade deles. Quando ganhamos uma linha de trem para conversar com o quarto guri, que estava trabalhando em um rio, percebi que nosso equipe tinha aumentado. Pois é, os moleques que eu tinha entrevistado agora eram parte da nossa equipe. Miguel tinha aliciado os jovens bandidos para a nossa equipe e eles vieram trabalhar com a gente. Carregavam suas armas e nossas luzes, carregavam suas armas e nossas bolsas, seguravam os microfones e plugavam os microfones de lapela com o farto conhecimento de quem há pouco tinha sido submetido aos mesmos procedimentos. Naquele momento eles estavam sujeitos às nossas reclamações e até a uns esporrinhos. Naquele momento viase exatamente a diferença entre o homem e o monstro. Eles não eram nem uma coisa nem outra, eles eram apenas meninos. Meninos da Paraíba. (Athayde, 2005, p. 30-31).

\section{Ciência no Cotidiano - Uma Atividade Moral Igual a Muitas Outras}

Para boa parte das pessoas, incluindo os psicólogos no cotidiano, não haveria nenhum problema com a proposta de que pesquisa é a atividade própria de cientistas e que, desde que cientistas são formados e treinados corretamente e seguem os métodos e procedimentos certos, tendem a agir para o bem público. Outras poderiam ter dúvidas sobre sua competência porque afinal há muitos cientistas hoje em dia e não se pode necessariamente confiar na sua formação. Entretanto, para estas pessoas, não haveria nada fundamentalmente errado com 
a proposição que ciência é um empreendimento neutro que gera conhecimentos válidos e úteis. Se há um problema, seria somente com aqueles cientistas que não se comportam corretamente. Isso é, que usam métodos inadequados, formulam as perguntas erradas, estudam temas que não precisam ser estudados, não tratam as informações confidenciais de maneira confidencial ou não respeitam as populações que estudam. A razão para o qual temos comitês de ética (uma rede complexa de materialidades e socialidades) e outros mecanismos de julgamento de valor (por exemplo avaliação por pares e a obrigatoriedade da discussão metodológica) é justamente porque estamos preocupados que nem todos vão se comportar corretamente. Em outras palavras sabemos o que é correto (o que são tópicos válidos, questões válidas, métodos válidos e procedimentos válidos).

Na historia da psicologia social há alguns estudos que são considerados clássicos por razões diversas. Um, feito por Marie Jahoda, Paul Lazersfeld e Hans Zeisel em 1931, versa sobre os efeitos de desemprego na pequena comunidade da vila de Marienthal perto de Viena (M. J. P. Spink, 2007). No relatório que foi publicado na época, não há discussão de método e muito menos uma introdução teórica; somente uma descrição das diferentes maneiras que usaram para buscar informação sobre o cotidiano de uma comunidade desempregada. Não há menção ou mesmo discussão de consentimento informado ou de como eles resolveram as questões inevitáveis presentes no contato íntimo entre os pesquisadores e a comunidade. Os pesquisadores, jovens na época, estavam comprometidos politicamente com a busca de um mundo melhor e eles criavam o estudo na medida em que este avançava; desenvolvendo diferentes maneiras de compreender o que passava com pessoas nas suas atividades diárias. Para usar a expressão, "seus corações estavam no lugar certo" e isso era suficiente. Quando Lazersfeld mudou para os Estados Unidos retardou durante muito tempo a publicação do estudo em inglês, preocupado pelo fato que não havia nenhuma discussão de método. A visão dos três sobre ética não era de uma lista de itens a serem verificados para fornecer uma garantia moral de bom comportamento. Era uma visão performática de ética, como algo constitutivo da prática diária e sobre a qual somos discursivamente competentes.

Porque então, a preocupação excessiva da psicologia social hoje em dia com objetivos, métodos, questionários e consentimento informado, ao ponto de desconectar-se do cotidiano, de se distanciar do outro e de tornar a ação de investigação algo especial? São muitas as razões que podem ser dadas incluindo a economia de tempo e as obrigações da produtividade acadêmica. Mas, sem dúvida, parte de nosso problema é que herdemos uma visão hiper-exagerada de verdade. Uma verda- de que não é visto apenas como algo simples e prática, uma convenção que utilizamos quando conversamos sobre eventos, acontecimentos e conexões causais, mas como algo superpoderoso e completo, algo que realmente existe, uma "super" verdade que nem a filosofia nem a religião foram capazes de descobrir e cuja busca passou para as mãos da ciência empírica. Rorty referiu-se a esta como sendo a busca pela verdade redentora, a crença que há "algo atrás daquilo que aparece, uma única e verdadeira descrição sobre o que passa, o segredo final" (2000, p. 2).

Dado que os cientistas se identificam como guardiões do futuro da humanidade, eles se considerem pessoas moralmente especiais, treinadas cuidadosamente e que seguem seus caminhos de maneiras igualmente especiais. Eles devem cuidar da mensuração; suas observações devem ser objetivas e procedimentos corretos devem ser seguidos para evitar a contaminação do observado pelo observador e para garantir que os resultados serão capazes de serem considerados válidos. Quando utilizam abordagens qualitativas, precisam demonstrar que os entrevistadores foram treinados adequadamente, que os registros foram feitos corretamente e que métodos apropriados de análise foram utilizados. Para as pessoas que saem dos laboratórios ou salas de entrevista com portas fechadas e entram no campo, há a obrigatoriedade de tratar o campo da mesma maneira. Há tratados imensos sobre o uso da etnografia, sobre registros de campo e sobre pesquisa participante porque não é muito fácil convencer alguém de que sentar em cafés, andar nas ruas, escutar conversas alheias, conversar em filas e olhar a arquitetura urbana é ciência; mesmo sendo isso que fizeram em Marienthal.

Agora, ninguém duvida e nem disputaria a necessidade de alguma forma de discussão coletiva sobre a validade daquilo que está em estudo na psicologia social, como também não está em dúvida a idéia de verdade como uma noção cotidiana utilizada por pessoas como parte de suas atividades corriqueiras. É uma convenção social que nos permite dizer " $2+2=4$ ", "choveu ontem", "inclusão social e exclusão social são idéias vinculadas mas sutilmente diferentes" e de construir tempos de verbo para lidar com diferentes graus de certeza. Entretanto, conforme aponta Rorty:

O problema de tratar o cientista empírico como um paradigma de virtude intelectual é que o amor pela verdade do astrofísico não parece muito diferente do filólogo clássico ou o historiador orientado para os arquivos. Todas estas pessoas estão tentando fazer algo de maneira certa. Como também, o mestre carpinteiro, o contador habilidoso e o cirurgião cuidadoso. A necessidade de acertar é central para a identidade de todas estas pessoas; central para aquilo que faz suas vidas válidas. (Rorty, 2000, p. 8). 
A resolução prática de problemas - tentando acertar - é algo em que psicólogos sociais, encanadores, cozinheiros, agricultores familiares, comunidades e vizinhanças se considerem, todos, competentes. Ao aceitar os desafios de cada dia e ao resolver problemas, o conhecimento atual se modifica e, com um pouco de sorte, as coisas melhoram.

Entretanto, dada a coexistência de muitas pessoas diferentes tentando, cada à sua maneira, acertar, e dado que a curiosidade social cotidiana e a psicologia social compartilham a mesma divisa, uma pergunta delicada se coloca: são os procedimentos corretos que produzem o conhecimento ou são as conversas orientadas para tentar acertar? O que é mais importante, uma lista de pontos a serem verificados para determinar a validade do método ou uma disponibilidade para o diálogo? Se a idéia de tentar resolver coisas juntos, de compartilhar as preocupações e angústias como também os prazeres dos sucessos é uma descrição razoável de como nós, coletivamente e em geral, enfrentamos a vida, porque deve ser diferente na psicologia social?

Declarar-se parte de um campo-tema é demonstrar a convicção ética e política de que, como psicólogos sociais, pensamos que podemos contribuir e que estamos dispostos a discutir a relevância de nossa contribuição com qualquer um, horizontalmente e não verticalmente. Horizontalmente, porque não há nenhuma grande verdade mantendo quentes as nossas costas; nenhum instrumento de inquisição que podemos mostrar para garantir obediência às nossas idéias. Só podemos argüir e discutir, tal como os demais. Temos algo a contribuir porque temos um mínimo de disciplinariedade que inclui a vontade de discutir entre nós a validade daquilo que fazemos - como também fazem entre si os especialistas em transplantes de coração, os cozinheiros, os jardineiros, os pedreiros e os presidentes. Somos somente uma parte de uma ecologia de saberes, cada uma das quais partindo de um ponto distinto e pensando que tem algo a contribuir.

Ao discutir uma versão inicial deste texto com Jacqueline Brigagão, psicóloga social e professora na área de obstetrícia, ela lembrou de um evento ocorrido numa investigação sobre parto humanizado em uma casa de parto que resume, melhor de qualquer argumento acadêmico, o nosso ponto principal.

Uma aluna do curso, Claudia, entrevistava uma jovem que só tinha completado o primeiro grau de ensino fundamental sobre seus motivos da escolha pelo parto humanizado. A jovem respondeu que havia pesquisado muito o tema na internet e começou a descrever aquilo que ela aprendeu sobre o parto humanizado na França e em outros países - alias muito mais do que sabia a entrevistadora. Neste momento Claudia, sensatamente, colocou suas questões de lado e entrou na conversa.

\section{Referências}

Athayde, C. (2005). Meninos da Paraíba. In C. Athayde, MV Bill \& L. E. Soares. Cabeça de porco (pp. 30-31). Rio de Janeiro, RJ: Objetiva.

Barthes, R. (1982). Mitologias. São Paulo, SP: DIFEL.

Bauman, Z. (2005). Identidade: Entrevista a Benedetto Vecchi. Rio de Janeiro, RJ: Jorge Zahar.

Bertuol, C. (2003). A criança e o estatuto da criança e do adolescente - Um estudo sobre a polissemia da criança nos espaços públicos. Dissertação de Mestrado não-publicada, Programa de Estudos Pós-graduados em Psicologia Social, Pontifícia Universidade Católica de São Paulo, SP.

Canelon Perez, J. (2004). A gestão de água no Vale de Quibor: Uma análise psicossocial de uma forma tradicional de manejo de um bem comum. Tese de Doutorado não-publicada, Programa de Estudos Pós-graduados em Psicologia Social, Pontifícia Universidade Católica de São Paulo, SP.

Garfinkel, H. (1967). Studies in ethnomethodology. Englewood Cliffs, NJ: Prentice Hall.

Gomes, J. A. (2005). A comuna da terra: Itinerários de sentidos e marchas de pessoas em situação de rua que buscam sua participação social. Quito, Equador: ABYA - YALA.

Habermas, J. (1984). The theory of communicative action. Boston, MA: Beacon Press.

Latour, B. (2004). Politics of nature. Cambridge, MA: Harvard University Press.

Law, J., \& Mol, A. (1995) Notes on materiality and sociality. The Sociological Review, 43(2), 274-294.

Lessig, L. (2002). The future of ideas: The fate of the commons in a connected world. New York: Vintage Books.

Lewin, K. (1952). Field Theory in Social Science-Selected theoretical papers by Kurt Lewin (D. Cartwright, Ed.). London: Tavistock Publications.

Marques, B. de S. (1985). Reflexão em torno dos conceitos de lugar, povoação e aglomerado populacional. Revista da Faculdade de Letras - Geografia. Serie 1, Porto,(1),89-110.

Menegon, V. M. (1999). Por que jogar conversa fora? In M. J. Spink (Ed.), Práticas discursivas e produção de sentidos no cotidiano: Aproximações teóricas e metodológicas (pp. 215241). São Paulo, SP: Cortez.

Menegon, V. M., \& Spink, P. (2005). Micro-lugares como produto e autor de sentidos. Trabalho apresentado no XIV Encontro Nacional da Associação Brasileira de Psicologia Social, Belo Horizonte, MG. (Mimeo).

Rorty, R. (2000). The decline of redemptive truth and the rise of a Literary Culture. Retirado de http://www.stanford.edu/ rrorty/ decline.htm

Sato, L. (1991). Abordagem psicossocial do trabalho penoso: Estudo de caso de motoristas de ônibus urbano. Dissertação de Mestrado não-publicada, Programa de Estudos Pós-graduados em Psicologia Social, Pontifícia Universidade Católica de São Paulo, SP.

Sato, L. (2007). Processos cotidianos de organização de trabalho na Feira Livre [Edição especial]. Psicologia e Sociedade, 19(1), 95-102.

Sousa Santos, B de. (2007). Renovar a Teoria Crítica e reinventar a emancipação social. São Paulo, SP: Boitempo.

Spink, M. J. P. (2007). Pesquisando no cotidiano: Recuperando memórias de pesquisa em Psicologia Social. Psicologia e Sociedade, 19(1), 7-14 
Spink, P. (2003). Pesquisa de campo em Psicologia Social: Uma perspectiva pós-construcionista. Psicologia e Sociedade, 15(2), $18-42$.

Peter Kevin Spink possui graduação em Psicologia pela University of London e doutorado em Psicologia Organizacional pelo Birkbeck College. É professor titular da Escola de Administração de Empresas de São Paulo da Fundação Getúlio Vargas e também Coordenador de seu Centro de Estudos em Administração Publica e Governo (CEAPG). Endereço para correspondência: Fundação Getulio Vargas, Centro de Administração Publica e Governo, Avenida 9 de Julho, 2029, Bela Vista, São Paulo, SP, 01313-902. Tel.: (11) 3281 7904; Fax: (11) 2875095.

peter.spink@fgv.br

\section{O Pesquisador Conversador no Cotidiano}

Peter Kevin Spink

Recebido: 18/10/2007

$1^{a}$ revisão: $14 / 01 / 2008$

Aceite final: 24/01/2008 